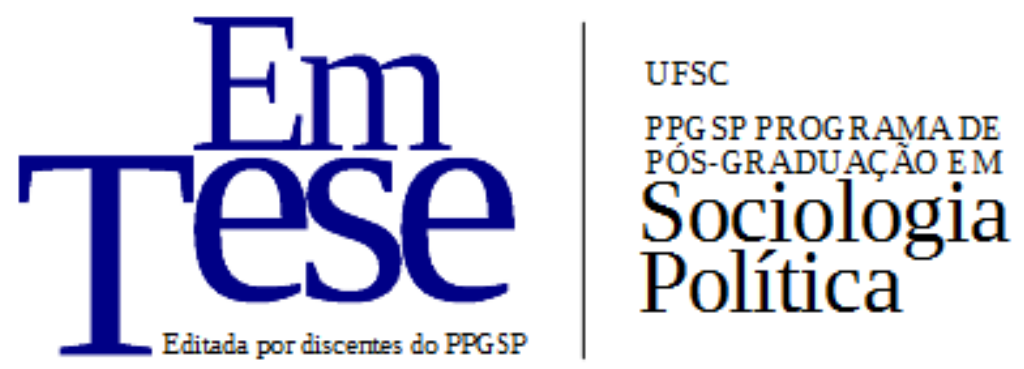

v. 13, n. 1, jan./jun., 2016

\title{
O que se entende por educação: as abordagens da sociologia clássica de Durkheim, Weber e Marx
}

\author{
Fabiane Medina Cruz ${ }^{1}$
}

\section{Introdução}

Nas Ciências Sociais aprendemos que educação é um tema vital, mas que não é neutro. Que é o pilar essencial da vida moderna e que se apresenta sempre acompanhado de um punhado de referências. Não obstante, na maioria das vezes que o tema se apresenta, quer se referir ao conservadorismo das relações tradicionais de uma sociedade, e a solução de como conter as situações de crise. É por esse motivo que se faz um tema caro para toda a sociedade, pois para que se possa interferir na educação, há de levar-se em conta que terá que interferir nas referências que estão no pressuposto do entendimento do que é educar.

$\mathrm{Na}$ Sociologia não é diferente, somos educados para compreender que o conhecimento é peça chave das relações de poder, e que faz parte da ideologia dominante que ele seja apresentado como neutro. Por esse motivo, as respostas que se articulam em torno de o que entendemos por educação são as respostas que irão objetivar as noções que temos a respeito de viver em sociedade. Consequentemente serão essas noções que serão engendradas no planejamento e execução da educação, seja como ciência aplicada na

\footnotetext{
1 Mestra em sociologia pela Universidade Federal da Grande Dourados. Email: medinafabicruz@yahoo.com.br.
}

UFSC, Florianópolis - http://dx.doi.org/10.5007/1806-5023.2016v13n1p161 ISSN: 1806-5023 
sistematização do conhecimento burocrático da vida moderna, ou enquanto prática pedagógica, igualmente sistematizada, mas de cunho popular e insubmisso. Mais especificamente, quero dizer que indagar a respeito do que vem a ser educação, são medidas necessárias para detonar enraizados pressupostos que estarão por trás da retransmissão de juízos de valores civilizadores.

Observamos por essa premissa que a transmissão do conhecimento, enquanto instituição a cargo do poder público de uma sociedade, no sentido preliminar e último de dar sentido substancial ao pacto entre os membros de um conjunto coletivo, filtrado a partir de códigos normativos e morais, em conformidade com as premissas culturais da noção de aglomerado (mega ou micro) social, é denominado pela Sociologia de instituição.

São as instituições que dão sustentação às bases das relações entre os membros pactuantes e regulam limites aos não pactuantes do projeto em curso. Certamente, por serem elas que informam as potencialidades e limitações de suas ações.

É esta razão que faz da educação um programa político, muito mais do que um simples método para o ensino, tal qual é difundida pela concepção ideológica que nos é hegemônica da educação. Também é neste sentido que a Sociologia, a partir das suas perspectivas pilares aplicada à leitura da educação - enquanto instituição - é importante para contribuir com o esclarecimento da sua função social e natureza política desse objeto de análise.

É a partir do exercício constante de lembrar que a Sociologia trabalha sob a premissa de produzir conhecimento a respeito da sociedade moderna, urbana e industrial, delimitada essencialmente pelo referencial do ocidente enquanto espaço global, e que este, por sua vez, executa a difusão espacial do ocidente, enraizada na concepção ideológica da neutralidade do Estado-nação, é que fortalece o advento sociológico mais significativo de todos os tempos, que foi perceber que nós, seres humanos, como seres naturalmente sociais (e socialmente políticos), somos capazes de interagir, organizarmos, e mudar o mundo. Entretanto, será a partir das noções que fazemos dos significados da vida em comunidade que iremos conduzir o nosso desenvolvimento no mundo e o desenvolvimento do mundo que nos rodeia. 
Foi assim, por exemplo, na Revolução burguesa, mudança radical dos fatores sociais que marcou o nascimento do Estado moderno, nutrido a partir de ideais iluministas que conseguiu suplantar a ordem feudal eclesiástica, de sustentação do antigo regime, a monarquia; por uma ordem de paradigmas tecnocráticos centrados na combinação de poderes do Estado-nação e organização social a partir de contratos jurídicos.

É por este motivo que apresento, neste presente trabalho, algumas reflexões sociológicas da educação, relacionando entre os três pilares principais da Sociologia que, de modos distintos ou complementares, contribuirão em perceber como concebemos o mundo, e como esse mundo formula nossas concepções.

Os estudos elaborados por Emile Durkheim, Max Weber e Karl Marx correspondem às respostas que estabelecem paradigmas a cerca de temas recorrentes e cotidianos, tal como cidadania, desenvolvimento econômico e identidade nacional, entre outros - assuntos que inequivocamente se desenvolvem e ganham materialidade através do terreno da educação.

Como já citado, sabemos que tais concepções tenham se configurado no contexto das revoluções industriais e burguesa, e que são esses os marcos que delimitaram a organização da sociedade quando, na virada para o mundo moderno, as visões foram articuladas em padrões hegemônicos ocidentais das concepções do comportamento do cívico (político não-estatal, ou sociedade civil) e da expressão moral (ou subjetiva) dos seus pactuantes. São eles que até hoje dão o sentido a temas como esses, que são elencados, a partir desse referencial monolítico, que ainda, são atuantes na contemporaneidade.

Nesse caso, desde os séculos XVI a XIX, os edifícios filosóficos, morais e conceituais formam a base para o que vivemos no hoje - cito essa visão temporal pelo sentido da necessidade de repensá-los mais seriamente sob perspectiva da descontinuidade dessas noções, e para apontar que é chegada a hora de reformulá-los.

Finalmente, me oriento por Marx, Weber e Durkheim por se firmarem os principais expoentes do pensamento social dos períodos de mudança, visto que, até hoje suas reflexões são ainda cabidas para apontar e analisar o valor que tem a educação, o difusor da cultura, do treinamento e dos costumes arraigados de um passado que, tendo em vista nossa

UFSC, Florianópolis - http://dx.doi.org/10.5007/1806-5023.2016v13n1p161 ISSN: 1806-5023 
localidade histórica, talvez nunca tenha nos representado, por estar formulado por referenciais eurocêntricos de cidadania.

\section{Durkheim e a socialização conservadora}

Segundo Martins (1981), a sociologia durkheimiana é marcada pela preponderância da divisão de dois mundos. Esses mundos distintos correspondem a tipos diferentes de sociedade (sociedades capitalistas e pré-capitalistas), que estão qualificadas respectivamente a partir do tipo de solidariedade que é alimentada entre seus membros.

Sendo assim, as solidariedades, mecânica ou orgânica, na sociologia de Durkheim, são formulações encetadas para qualificar o nível de desenvolvimento técnico de determinado grupo social, promulgando a sua posição frente ao mundo moderno e ocidental, tal qual se moldava no período de estabelecimento da sociologia consolidada por Durkheim.

Consequentemente, nesta separação das diferenças de estruturas entre os grupos sociais, a sociologia durkheimiana estabelece um elemento elementar que servirá para pontuar a solidariedade manifesta em determinados grupos - investigando se esta é orgânica ou mecânica. É neste ponto, então, que Durkheim deixa em evidência que a "base da sua concepção sobre solidariedade mecânica e orgânica está pautada na divisão do trabalho" (MARTINS, 1981, p 20).

Neste sentido, é a divisão do trabalho que, para Durkheim, irá diferenciar o estágio em que se encontra essa sociedade em tramitação para o universo moderno, pois serão esses laços firmados entre os indivíduos, na perseguição de suas especialidades fragmentárias (ou não), na relação com o trabalho que irão conformar a visão de mundo desses indivíduos. Em consequência, tais relações irão mediar às relações deste para os demais indivíduos, e para com as instituições que lhes promulgam. E essas premissas serão determinantes, segundo Durkheim, para alimentar as estruturas que irão reger a sociedade como um todo.

Compreende Martins (1981, p. 21) que "a solidariedade como expressão dos fundamentos da vida social, e, sobretudo, a solidariedade mecânica como o critério principal de compreensão da sociedade moderna, ou seja, como seu pressuposto", alinha o

UFSC, Florianópolis - http://dx.doi.org/10.5007/1806-5023.2016v13n1p161 ISSN: 1806-5023 
princípio fundamental da sociologia, com o pensamento da economia política do capitalismo, só que, imediatamente, de maneira secularizada, na qual a relação mediatizada pelas coisas, ou fatos sociais, formam bases para as noções de relacionamentos interpessoais, e estes serão essencialmente capitalistas.

Ao percorrer o pensamento de Durkheim, de que as instituições sociais são fatos sociais e devem ser tratadas como coisas, esta será também a dimensão propícia para a própria instituição. Ou seja, Durkheim, com isso, está fazendo uma projeção sociológica do pensamento hegemônico do capitalismo que, aqui revestido de uma concepção comunitária conservadora, institui-se como a forma adequada de funcionamento de uma sociedade. Mas não qualquer sociedade, mas sim esta, marcada pela individualização e pela estruturação tensa do modo de integração interior do sujeito, ao exterior coercitivo, ou a sociedade em suas regras e códigos morais, que se alimenta de sentido, a partir da objetividade das coisas, destituindo surpreendentemente a condição humana dessas coisas. Enfim, coisificando a atividade humana, tanto quanto seus resultados (ao nível social, as instituições) (MARTINS, 1981, p. 20-21).

Nesse caso, supõe-se automaticamente que Durkheim não inaugura uma imaginação sociológica original, mas alinha a nova ciência ao funcionamento hegemônico que se moldava em torno das novas relações, ditas modernas.

Portanto, será neste sentido que o pensamento durkheimiano definirá a educação através do tratamento quanto a sua natureza e função como há citado em Educação e Sociologia (DURKHEIM, 1978).

É neste trabalho, principalmente, que o pensador expõe seu padrão de pensamento conservador sobre a educação, quando se esforça em afirmar que o poder coercitivo da sociedade se expressa na educação, já que, assim, a "educação é a ação dos membros de diferentes gerações uns sobre os outros; é a ação que os adultos exercem sobre as crianças" (DURKHEIM, 1978, p.33). Varia com o tempo e o meio, pois cada sociedade considerando seu momento de desenvolvimento possui um sistema de educação que se impõe ao indivíduo, devendo ser considerado também que os sistemas de educação se formam e desenvolve segundo as outras instituições da sociedade, tal qual religião, organização política, ou mesmo grau de aperfeiçoamento da ciência, do Estado, das indústrias, etc.,

UFSC, Florianópolis - http://dx.doi.org/10.5007/1806-5023.2016v13n1p161 ISSN: 1806-5023 
fazendo parte, portanto, de um arcabouço de realidades que não podem ser criadas, destruídas ou transformadas a vontade (DURKHEIM, 1978).

Ainda com esse quadro Durkheim se referirá, mais especificamente, às etapas que consubstanciam a interação entre indivíduo e sociedade. Denotará seus referenciais iluministas, já que seu pensamento tem na educação (técnica, mecânica, orientada para a divisão do trabalho), a fonte principal capaz de dar direção ao conjunto de pessoas livres cooperando entre si, ou, sob influência da mão invisível do mercado de negócios.

É nesse ponto que o sociólogo chega a concluir que quando esse mecanismo falha na sua função compromete as outras instituições de modo generalizado, instalando-se a partir de então, o caos, a anomia e o desregramento entre as sínteses individuais pois, para Durkheim, as maneiras de agir, de pensar, de sentir, existem fora das consciências individuais, e são fatos sociais, ou seja, coisas, que expressam as instituições políticas, econômicas e religiosas, firmada nas ideias morais, no direito, na família, todos eles, elementos conservadores que serão retransmitidos através da educação.

A educação, então, conforme Durkheim, varia de acordo com a classe social e região que se aplica, pois há diferenças claras entre as ações educativas praticadas na cidade e as ações que são praticadas no campo, por exemplo. Entretanto, alguns elementos comuns de todas as ações de educação, sobretudo, precisam ser observados: "um conjunto e ideias acerca da natureza das coisas devem ser conservadas no ato de repassar valores educacionais, pois toda e qualquer educação tem por objetivo, fixar ideias na consciência do educando" (DURKHEIM, 1978, p.40).

É claramente neste ponto que o pensador expressa o ápice do sentido marcadamente conservador dos ideais hegemônicos, uma vez que não hesita em apontar valores elementares a ser considerados na replicação da transmissão do conhecimento, chamando atenção para o cuidado na obtenção do controle dos conteúdos, visando a coesão do projeto de cooperação entre os membros do corpo social, de forma que não sejam causados desequilíbrios entre as concepções delimitadas à esta sociedade.

Sendo assim, ainda acrescenta:

Os ideias que conformam a parte básica da educação tem por função suscitar na criança: um número mínimo de estados de consciência que a

UFSC, Florianópolis - http://dx.doi.org/10.5007/1806-5023.2016v13n1p161 ISSN: 1806-5023 
sociedade considere indispensável; e um determinado estado físico e moral que corresponda com a sua classe, casta, grupo, família, profissão (DURKHEIM, 1978, p 40)

Nesse caso, como percebemos, as características de coercitividade e determinismo social devem declaradamente se impor aos indivíduos, na concepção de alimentar sentimento subjetivo de classe. Durkheim é categórico em entrar em defesa da segregação, fixando a orientação em exercer coação à conduta e ao pensamento de cada um, do ponto de vista do lugar que esses ocupam na estrutura das classes sociais.

Durkheim afirma inclusive que "é uma ilusão acreditar que podemos educar nossos filhos como queremos, pois há costumes que somos obrigados a observar" (DURKHEIM, 1978, p.36-37). E justifica que a sociedade não poderia existir sem a consideração de determinados padrões de homogeneidade entre seus membros. Nesse caso, o que está implícito é o ideal de salvaguardar a sociedade burguesa através da difusão dos seus valores hegemônicos, no intuito de homogeneizar as identidades nacionais.

Dessa forma, é mister que a educação perpetua e reforça esses padrões, pois atua "fixando de antemão na alma da criança certas similitudes, necessárias para a vida coletiva" (DURKHEIM, 1978, p. 40-41): a vida ocidental, urbana e burguesa.

É por isso que a educação constitui-se a dimensão fundamental para a análise sociológica, demonstrada por Durkheim, pois sendo ela um fato social, coletivamente produzido, ultrapassa as escolhas e preferências pessoais - age na contenção das diferenças, pois, tem a função instrutiva primordial de estar acima dos interesses individuais (princípio ideológico), prezando pela reprodução e segurança da própria sociedade. Durkheim é categórico afirmando que não se pode conceber uma educação que ameace a existência da sociedade que a pratica.

Para compreender o significado de seu raciocínio, voltemos a algumas das noções chave de Durkheim. Interesse coletivo, reprodução da segurança, ideais exteriores e coercitivos, determinação sócio-político das marcas de classe no apelo da formulação educacional, anomia, caos social e desintegração.

Essas preocupações fizeram parte do pensamento de Durkheim porque durante a Terceira República francesa $(1870$ - 1940), marcada pela instabilidade política e as guerras

UFSC, Florianópolis - http://dx.doi.org/10.5007/1806-5023.2016v13n1p161 ISSN: 1806-5023 
civis (sociedade contra Estado), a sociedade tradicional européia emitia sinais de fraqueza em suas instituições, enquanto fontes de solidariedade. A família e a religião não processavam mais suas antigas funções de integração entre os entes, e novas fontes de consenso eram necessárias para fortalecer a sociedade e manter a sua coesão (QUINTANERO; BARBOSA; OLIVEIRA, 2010).

Por fim, uma nova moral social não poderia desenvolver-se proeminentemente se não encontrasse habitat de equilíbrio e harmonia que favorecesse o seu florescimento. Com o afastamento da solidariedade orgânica, impetrada pela organização religiosa anterior, as corporações assumiriam o dever de cumprir, desse momento em diante, as condições necessárias à regulação que o corpo social necessitava, impondo-lhe autoridade que the pusessem deveres, regras e limites (QUINTANERO, 2010).

Assim, em Durkheim, a transmissão do saber assentava-se na difusão de valores morais e na divisão do trabalho. Para tanto, seria de inteira necessidade que a educação assumisse caracteres seculares e científicos, trazendo em seu conteúdo a inculcação da moral e da qualificação, no realocamento dos indivíduos pela extensão da estrutura social (LOPES, 2012). Ou seja, a educação deve informar a cada qual o seu 'lugar' nessa estrutura. Pois, disso dependerá o bom desempenho de todo o corpo social hegemônico.

A educação é a ação exercida sobre as gerações que não se encontram ainda preparadas para a vida social; tem por objetivo suscitar e desenvolver certo número de estados físicos, intelectuais e morais, reclamados pela sociedade política, no seu conjunto, e pelo meio especial a que (o indivíduo), particularmente, se destine (DURKHEIM, 1978, p.41).

Dessa maneira, há uma atribuição importante do determinante histórico na manutenção e equilíbrio das instituições da sociedade, incluindo a educação, pois o surgimento da ciência social nesse instante, celebrado pelo pensador - fruto de um trabalho, iniciado por filósofos como Saint-Simon e depois Auguste Comte - de secularização dos valores e crenças para um novo organismo social, fazendo jus a novos e modernos parâmetros de formação, onde a formação eclesiástica não tivesse tanta força, nem tanta importância, como era atribuída às circunstâncias históricas anteriores. 
O que tem de notável no projeto de Durkheim é a riqueza de suas percepções, sendo justamente o que faz de sua obra marcante. Suas investigações, de certa forma curiosa (como o estudo do Suicídio, por exemplo), servem de base para compreensão das formas como está concebida a produção do conhecimento na era ocidental moderna. Quintanero (2010) observa que sua influência é particularmente visível no caso dos estudos sobre os sistemas simbólicos de representação.

Por conseguinte, o pensamento Durkheimiano, a respeito das representações coletivas e dos sistemas lógicos de compreensão do mundo, e os aspectos ligados ao consenso e à integração hegemônica do sistema social vigente, foram incorporados à moderna teoria sociológica (QUINANERO, 2010, p. 95). Sendo assim, suas idéias inspiram até hoje os estudos sobre os padrões tradicionais de interação - dentro dos processos de urbanização, além de pesquisas sobre a família, a profissão e a socialização.

Dos itens apontados nesse breve esboço do pensamento de Durkheim, a socialização conservadora, se firmam como o mais insigne conceito dedicado ao autor.

É a partir das formulações a acerca dos padrões lógicos dos estágios de aprendizado da criança que as ideias de integração do indivíduo em formação ao sistema social se apresenta em seu maior potencial de sistema fechado, de valor coercitivo. Assim como suas categorias inter-relacionadas, de adesão ao pacto social, são metas da prática de socialização, para que assim corresponda à integração granular das novas gerações às estruturas das correspondentes sociedades. Grosso modo, especifica como o sistema social capitalista se reproduz, a partir das consciências para cooperação alienada.

O ser humano, segundo Durkheim, é constituído de duas partes: uma parte que se relaciona apenas conosco mesmo e com a vida pessoal; e a outra que é um sistema de ideias e sentimentos, que se exprimem no grupo a que fazemos parte.

Em síntese, na realidade efetiva esse espírito social não nasce com as pessoas mas, no entanto, ele deve ser absorvido durante o processo de adaptação desse ser ao meio em que ele vive, sendo este rigor que vai revelar a importância e a fecundidade do trabalho educativo - trabalho que tem na virtude de satisfazer antes de tudo as necessidades sociais vigentes, e não de outra natureza, ou de natureza contestatória.

UFSC, Florianópolis - http://dx.doi.org/10.5007/1806-5023.2016v13n1p161 ISSN: 1806-5023 
Peter Berger e Thomas Luckmann (2002), a respeito do propósito de socialização, nos auxiliam no que chamam de processo dialético fundamental do desenvolvimento da consciência social, e o explicam a partir de três passos principais: o momento de exteriorização, de objetivação e interiorização. Dizem que só é possível manter uma compreensão dos elementos por inteiro se considerarmos conjuntamente esses três momentos convergentes.

A exteriorização é a contínua efusão do ser humano sobre o mundo, seja na atividade física, como também na atividade mental da pessoa. A objetivação é a imposição por parte das representações coletivas de uma realidade que se defronta com o indivíduo, caracterizada por uma facticidade exterior e distinta a eles. Já a interiorização é a reapropriação dessa mesma realidade por parte de cada um dos selfs, transformando-a novamente de estruturas do mundo objetivo em estruturas da consciência subjetiva.

Assim, "é através da exteriorização que a sociedade é um produto humano. É através da objetivação que a sociedade se torna uma realidade sui generis. E através da interiorização é que o ser humano é um produto da sociedade" (BERGER \& LUCKMANN, 2002, p. 16).

Todavia, como o foco de Durkheim é o desenvolvimento e equilíbrio da sociedade moderna e hegemônica e a 'perpetuação da sua espécie social', vê a educação como atividade eficiente para a transferência de valores e assimilação das regras para seus membros desde a tenra idade. Para tanto, o trecho abaixo esclarece:

(...) o ser humano é curiosamente inacabado ao nascer (...). Isto é, o processo biológico [sic] de "tornar-se homem" (ou mulher) ocorre num tempo que o infante humano se encontra em interação com um ambiente exterior ao seu organismo, e que inclui o mundo físico e o mundo humano da criança (BERGER \& LUCKMANN, 2002, p. 17, grifos meus).

Em outras palavras, há na sociedade um conjunto de regras formuladas e reproduzidas pela interação da coletividade entre si, essas regras são transmitidas às crianças através do processo de socialização. É esta educação que atende as preocupações durkheimianas, sobretudo, no ato de formar os indivíduos para cooperação e integração da vida coletiva. Logo, esta vida coletiva corresponde à lógica da vida burguesa, orientada

UFSC, Florianópolis - http://dx.doi.org/10.5007/1806-5023.2016v13n1p161 ISSN: 1806-5023 
para o consumo e a significação psíquica exterior mediada pelas coisas. Para o sociólogo, a educação não pode ser dada ao acaso, posto que deva cumprir um objetivo muito específico de formar o ser social - e transmitir as regras instituídas pelo corpo coletivo e ao mesmo subordiná-lo a elas - pois, segundo axiomas durkheimianos, dependerá o futuro deste projeto de humanização.

\section{Weber e o sistema perito}

Se Durkheim sinaliza sua tese para a moral da socialização, Max Weber aponta para a amoralidade da racionalização burocrática como modelo evidente da sociedade capitalista em expansão ainda mais eficiente dos níveis de conservação da estrutura dominante, pois a vida arrefecida pelo sistema da diplomação enquanto sinônimo de segurança das relações e posições social, fator que irá conferir o sentido à existência moderna e prestígio diferencial, fica evidente que exclui da possibilidade de ascensão, qualquer um dos membros em pé de igualdade. É a legitimação da meritocracia - um modelo que centra o ponto de partida nas condições seletivas de oportunidades próprias das sociedades de consumo.

A lógica para essa delimitação é simples. O modelo capitalista de sociedade moderna emprega a seleção e a competição entre pessoas 'capazes', envolvidas por uma moral profissional que toma a frente nas relações entre as pessoas. Sendo assim, “a educação é que irá contribuir para realização de uma seleção social" natural entre as pessoas (LOPES, 2012, p. 9). A sociedade é dessa forma separada em os indivíduos que possuem educação e os indivíduos que não possuem educação.

Educação neste sentido se transfigura de projeto de desenvolvimento da sociedade (conforme se apresenta em Durkheim) para refletir um sistema de burocracias mediadas pela posse de notas e títulos galgados pelo processo educacional que estabelece os estágios de postos profissionais e maturação da experiência de vida. O critério aqui está no fato de possuir ou não acesso ao caminho dos estágios probatórios da sua experiência profissional.

É exatamente a posição que se alcança nessas gradações ao conhecimento que irá delimitar o seu status social perante o grupo. Assim, é recorrente que alguém que tramitou por essa sequência de classificação receba o reconhecimento de sua posição, através do status de

UFSC, Florianópolis - http://dx.doi.org/10.5007/1806-5023.2016v13n1p161 ISSN: 1806-5023 
Doutor. O restante dos que não emergiram nessa via de reconhecimento estarão automaticamente de fora da competição por ter ou não ter educação. Sem dúvida, essa lógica valorativa e deturpada de educação é a lógica que nos situamos no momento histórico de ascensão social a partir de coisas.

Para tanto, Weber é importante em nos esclarecer que o pilar de esteio da nossa sociedade delimita-se pela "burocracia moderna", e esta funciona da seguinte maneira: as atividades são distribuídas de formas fixas; a autoridade é atribuída de forma estável. Esta última estará delimitada pelas normas relacionadas como os meios de coerção, enquanto que a qualificação seja prevista por regulamento. Essas afirmativas vão dar legitimidade a uma forma peculiar de autoridade e/ou administração de teor estritamente burocrático. A "posse de diplomas educacionais está ligada a qualificação para o cargo. Essas certidões ou diplomas fortalecem o ‘elemento estamental' na posição do funcionário” (WEBER, 1979).

O autor alemão considera que ao contrário do que se possa imaginar, a autoridade permanente e pública, de jurisdição fixa - uma característica ordenadora das sociedades capitalistas - não constitui uma norma histórica, e sim, a exceção. Isso quer dizer que tal característica, já existente anteriormente ${ }^{2}$, assume essa face estrita e bastante fechada de acordo com a atribuição de que lhe são conferidas pelo sistema de educação. Neste sistema, os princípios da hierarquia significam um sistema firmemente ordenado, firmado pela supervisão dos postos inferiores pelos superiores.

Isso acontece porque a administração burocrática, ou administração especializada, pressupõe habitualmente treinamento exclusivo e completo para a ocupação dos cargos. O desempenho do cargo segue regras gerais, estáveis e exaustivas. O conhecimento dessas regras representa um aprendizado técnico especial.

A ocupação de um cargo é uma profissão, e para isso pretere-se a exigência de um treinamento rígido que demanda capacidade de trabalho durante longo período de tempo (a experiência), assim como exames especiais (avaliações de desempenho). Em geral, são esses os pré-requisitos para o emprego na sociedade contemporânea.

\footnotetext{
${ }^{2}$ Isso quer dizer que o capitalismo não apenas é absorvido pela mente, num processo subjetivo da moral do trabalho, mas como também, ele já existia enquanto germe das relações as quais Durkheim irá chamar de précapitalistas, tal como foi expressa pela fase da história mercantil.
}

UFSC, Florianópolis - http://dx.doi.org/10.5007/1806-5023.2016v13n1p161 ISSN: 1806-5023 
Weber ainda completa que a posição de um funcionário tem a natureza de um dever. O ingresso num cargo é considerado como aceitação de uma obrigação específica, fiel, em troca de uma existência segura. Giddens diria que "a natureza das instituições modernas está profundamente ligada ao mecanismo da confiança em sistemas abstratos, especialmente confiança em sistemas peritos" (GIDDENS, 1991, p. 77).

Outra curiosidade que faz parte da natureza específica do sistema de confiabilidade moderna é que não se estabeleça nenhuma relação pessoal com esse sistema, e sim que sejam dedicadas finalidades impessoais e funcionais aos casos administrativos. No entanto, isso não é uma questão apenas de gerar a sensação de segurança nem tão somente de formar um espírito de confiança nas instituições burguesas, como no caso do mundo pré-moderno. Contudo, é necessário acrescentar às sínteses das exteriorizações, uma questão lógica, de cálculo entre vantagem e risco, que concorre por conferir ao sistema perito um verdadeiro repositório de crença aos valores morais especializados, e não nos entes individuais que, em contextos específicos, o "representam".

Dentro dessa perspectiva weberiana, podemos observar uma forte afirmativa de que mesmo os líderes religiosos, assim como o funcionário público e o líder político, hoje são apenas funcionários a serviço de um propósito societal, não passando de atores desempenhando uma ação própria ou uma finalidade objetiva, não cabendo espaço para morais ideológicas (segundo a neutralidade axiológica). Ainda assim, mesmo estando subentendido, habitualmente, que as 'ideias de valores culturais' - tais como Estado, igreja, comunidades, partidos ou empresa - consideradas como inerentes à comunidade, não obstante, proporcionam uma áurea ideológica para o pensamento dominante. Se não pararmos para perceber, não notaremos que há um 'comércio' de privilégios em volta desses sistemas profissionais. Desse modo, o funcionário moderno habitualmente desfruta de uma 'estima social específica'. Uma vez que sua posição na sociedade encontra-se assegurada, inclusive, por definições especiais, não só do código social, como também do código criminal contra 'insultos aos funcionários’ (WEBER, 1979).

O pensador alemão afirma ainda que cada vez mais nos voltamos para a predominância de uma forte procura de administração por especialistas, uma vez que atribuímos valor a uma camada forte e estável de "funcionários, predominantemente vindo

UFSC, Florianópolis - http://dx.doi.org/10.5007/1806-5023.2016v13n1p161 ISSN: 1806-5023 
de camadas social e economicamente privilegiadas devido à distribuição das posições de poder" (WEBER, 1979., p.233).

A burocracia, centro por onde gravitam as justificativas do sistema perito, promove um modo de vida 'racionalista', de conceito específico, pois se relaciona com um tipo de desenvolvimento de 'objetividade racional', ancorada num tipo específico de personalidade do perito profissional. Isso apesar de ter um efeito de longo alcance, chama-nos atenção para um indicativo: a natureza do treinamento como fim da educação. Aqui podemos destacar as instituições especialmente de instrução superior - universidades, academias técnicas, ensino médio, etc., pois são dominadas e influenciadas pela necessidade de tipo de ‘educação' que produz um sistema de exames especiais. A especialização é cada vez mais indispensável para a burocracia moderna (WEBER, 1979, p. 277).

O desenvolvimento moderno da plena burocratização coloca em primeiro plano, irresistivelmente, o sistema de exames racionais, especializados (...). A burocratização do capitalismo, com sua exigência de técnicos funcionários, preparados com especialização, generalizou o sistema de exames por todo o mundo (WEBER, 1979, p. 278).

Um prestígio social é conferido no sistema de títulos educacionais, a mobilidade social, na modernidade, assim como a segurança de vida, é distribuída em torno da especialidade que cada uma das pessoas adquire durante a sua trajetória técnica. Um sistema de seleção de cidadãos, pessoas de bem e dignitários de respeito está ancorado no nível de titulação alcançado por essa pessoa. Os problemas da vida só poderão ser supridos, após se galgar pelas esteiras do acúmulo de experiência tecnocrática.

\section{Marx pela aptidão popular da educação}

É certo que nem Marx nem Engels, os dois articuladores do pensamento crítico da economia política do capitalismo, escreveram obras diretamente relacionadas à educação, assim como ocorreu com Weber ou Durkheim. No entanto, ao longo dos exames do capitalismo empenhado por Marx, existem várias passagens que demonstram a posição que

UFSC, Florianópolis - http://dx.doi.org/10.5007/1806-5023.2016v13n1p161 ISSN: 1806-5023 
assumiam a cerca da circulação da informação e da produção do conhecimento, assim como da desigual oportunidade em acessá-las.

A aptidão pela Ação Popular que foi marcada pelo método dialético adotado por Marx na exposição do conhecimento (materialismo histórico) foi utilizada para demonstrar através de cálculos dos fatos históricos, o sentido político de assegurar a nobreza de determinado grupo, em vista da pobreza total de seus servidores.

Evidentemente, pela preocupação que demonstraram quanto ao processo de acessibilidade do conhecimento da situação precária dos trabalhadores da indústria, ainda no século XIX, como é expresso logo de fato no Manifesto do Partido Comunista (2001), fica evidente que Marx e Engels se dispuseram em favor de um outro modelo de sistematização do conhecimento, pois fica claro as suas denuncias que a obsessão por controle pelas classes dominantes é constante, como percebemos quando escrevem: "vemos que a burguesia moderna é produto de um longo processo de desenvolvimento, de uma série de profundas transformações no modo de produção e nos meios de comunicação" (MARX \& ENGELS, 2001, p 26).

Todavia, para conquistar seus objetivos, "a burguesia tem que imiscuir-se em toda a parte, instalar-se em toda a parte, criar relações em toda a parte" (MARX \& ENGELS,2001, p. 29), ou seja, tem que controlar todo o processo de formação do capital, versando sobre esse processo a reprodução da mão-de-obra que será empregada na produção:

O que era, no princípio, apenas ponto de partida, é produzido e perpetuado sempre de novo, por meio da mera continuidade do processo, da reprodução simples, como resultado próprio da produção capitalista. Por um lado, o processo de produção transforma continuamente a riqueza material em capital, em meios de valorização e de satisfação para o capitalista. Por outro, o trabalhador sai do processo sempre como nele entrou - fonte pessoal de riqueza, mas despojado de todos os meios, para tornar essa riqueza realidade para si. Como, ao entrar no processo, seu próprio trabalho já está alienado dele, apropriado pelo capitalista e incorporado ao capital, este se objetiva, durante o processo, continuamente em produto alheio. (...) Como o processo de produção é, ao mesmo tempo, o processo de consumo da força de trabalho pelo capitalista, o produto do trabalhador transforma-se continuamente não só em mercadoria, mas em capital, em valor que explora a força criadora de 
valor, em meios de subsistência que compram pessoas, em meios de produção que empregam o produtor (MARX, 1996, p. 203-204).

É, pois, o esboço sobre a composição de valor da mercadoria, retirado em benefício da classe dominante, a partir da geração de lucro subvertida à jornada de trabalho da classe operária, sem dúvida o maior indicativo do empreendimento desse expoente da Sociologia clássica. Por esse motivo, consideramos que Marx não tenha deixado de tratar da educação, embora não exista um artigo específico em nome exclusivo do tema.

Como observamos, foram tais afirmações que fizeram da condição dos trabalhadores, conhecimento prático, tático e teórico da reflexão sociológica que advoga pela mudança. Assim como provocou Marx no seu período histórico correspondente, a evolução da filosofia alemã.

Tendo em vista o cenário da filosofia alemã ser o espaço da erudição e berço dos debates em torno da burocracia rígida e ordeira do Estado moderno, não era um detalhe o instrumento legal do capital despojado pela Filosofia apresentar-se como "neutro", pelo papel principal conservador, para que fosse protegida intacta a verdade dos fatos. Se mantendo afastada dos horizontes dos trabalhadores legalmente livres, mas agrilhoados pelo acesso à informação sobre o projeto de embuste da burguesia, projeto ao qual guardara lugar para a massa operária enquanto parte lograda da história.

Este processo de seleção dos interlocutores do conhecimento, muito tem a ver com a Educação que serve hoje ao capitalismo e, consequentemente, faz parte do processo de conversão da pessoa em coisa para a mão-de-obra, para a exploração do trabalho e extração da mais-valia. Sendo assim, "é evidente que [essa] linguagem não poderia ser mais cínica, [Visto que ao] colocar no mesmo plano os custos das coisas e os custos de manutenção do homem é transformar o homem em coisa” (MARX, 1985, p. 55, grifos meus).

Desse modo, o capitalismo, através de suas instituições oferece uma educação de conteúdo moral voltado para o trabalho. No obstante, não se trata de qualquer educação, mas, sobretudo, daquela que orienta a externalidade das coisas, para o valor das pessoas mediado por bens, para que a pessoa seja concebida em trabalhador/a, pois assim, terá que vender-se ao mercado de trabalho. Necessariamente, o mercado de trabalho irá exigir um ensino que cumpra ocupar posições que atendam os postos a serem criados pelo sistema

UFSC, Florianópolis - http://dx.doi.org/10.5007/1806-5023.2016v13n1p161 ISSN: 1806-5023 
capitalista, flexível, provisório e fluido. Pois, assim será regulada a variação da mão-deobra, pois enquanto um trabalhador esteja ocupado, mantém-se um exército de trabalhadores reservas que não conseguem se colocar no mercado.

Esse movimento é criado pelo capitalismo para alimentar seus objetivos, apresentarse-á a sociedade por meio de um discurso hegemônico a cerca da educação, escamoteado pela necessidade de qualificada mão-de-obra. Isso representa o instrumento mais elementar de reprodução do sistema capitalista: o sistema de exclusão, vendido sob a forma de educação, cria um ambiente propício para o empobrecimento da consciência a cerca da garantia de prosperidade do capital, identificado por Marx como alienação do trabalhador.

A separação entre o produto do trabalho e o próprio trabalho, entre as condições objetivas do trabalho e sua força subjetiva de trabalho, era a base realmente dada, o ponto de partida do processo de produção capitalista. (...) [visto que] o próprio trabalhador produz, por isso, constantemente a riqueza objetiva como capital, como poder estranho, que o domina e explora, e o capitalista produz de forma igualmente contínua a força de trabalho como fonte subjetiva de riqueza, separada de seus próprios meios de objetivação e realização, abstrata, existente na mera corporalidade do trabalhador, numa só palavra, o trabalhador como trabalhador assalariado. Essa constante reprodução ou perpetuação do trabalhador é a condição sinequa non da produção capitalista (MARX, 1996, p. 203-204).

Em outras palavras, o capital cria para seu próprio consumo, a mercadoria trabalho ${ }^{3}$, e assim determina o processo de socialização na sociedade moderna, definindo com isso a maneira como seremos educados: para a volatibilidade do mercado, para precariedade das relações, para desumanização dos desejos.

Fenomenologicamente ${ }^{4}$ compreende-se, com isso, que o trabalhador irá imbuir-se da sua condição de coisa. Achando natural que sirva de mercadoria para enriquecer o patrão. Mas, entrementes, que deve obedecer, ser coerente e colaborar, pois disso dependerá a sua sobrevivência.

O capitalismo faz isso por meio da escola pública oferecida pelo Estado capitalista. Logo, pois, envolve a socialização do seu sujeito-coisa, ou mercadoria, desde a infância:

\footnotetext{
${ }^{3} \mathrm{O}$ termo se refere ao conceito de trabalho assalariado.

${ }^{4}$ Refere-se ao processo de assimilação do conhecimento sobre si, como esboçado na formulação de Peter Berger.
}

UFSC, Florianópolis - http://dx.doi.org/10.5007/1806-5023.2016v13n1p161 ISSN: 1806-5023 
a constante manutenção e reprodução da classe trabalhadora permanece a condição constante para a reprodução do capital. (...) A reprodução da classe trabalhadora implica ao mesmo tempo, a transmissão e a acumulação da habilidade de uma geração para outra (MARX, 1996, p. $205 ; 206)$.

Vários tradutores do pensamento marxista, por sua vez, dedicaram à questão da educação, a perspectiva dialética do método desenvolvido por Marx. Considerando como ela se torna importante na desarticulação da ideologia dominante a cerca da realidade do mercado de consumo, que coisifica a execução do processo educativo, como já dito, no intuito de alimentar a divisão do trabalho.

Maria da Glória Gohn (1994), é um dos exemplos de tradutora do pensamento marxista que traz para o debate o contexto histórico da relação entre desenvolvimento da consciência da classe operária e a educação. A autora tece considerações importantes a cerca da relação entre os movimentos sociais e a educação, que tem como elemento de união, a participação da construção das visões de mundo da classe trabalhadora, empregado na contrapartida histórica da ideologia dominante. Os movimentos sociais, afirma a autora, são instrumentos de mobilização da autonomia, já que, desde a socialização de suas crianças, educam pela politização sobre o real objetivo da divisão do trabalho e informa o quanto a segregação tecnocrata está submersa na razão da qualidade dos serviços que serão prestados pelo Estado às classes populares no capitalismo. Essa perspectiva abre caminhos, instaura novos horizontes para organização comunitária, e resgata o sentido substancial de solidariedade.

Expõe a autora que, infelizmente, é essa teia de possibilidades da construção do poder popular que fica esmaecida pela prática de contenção política do sistema capitalista, não nos deixando observar as possibilidades de viver em associatividade e de resgatar os valores humanos das relações interpessoais.

O liberalismo, como pensamento político do capitalismo controverte a questão da cidadania, dando ênfase à noção de direitos e descaracterizando o conteúdo deste conceito. Assim sendo, o leque que envolve os direitos naturais: liberdade e igualdade são colocados em mesmo grau de importância que a propriedade. E perante a mesma noção de justiça, 
subverte a noção de envolvimento entre os sujeitos sociais e deles para com seu território e para com as questões políticas de seu habitat.

Dessa maneira, a premissa da separação dos poderes em Executivo, Legislativo e Judiciário consolida a blindagem burocrática e fragmenta a administração do Estado, nitidamente paradoxal, no que tange ao seu composto gerencial. Isto quer dizer que o que uma das instâncias formularem por efetivação de direitos, pode perfeitamente ser desaprovado ou desarticulado por qualquer das outras fontes de gestão do poder público. Em síntese, faz parte do arcabouço da moral conservadora formulada regular o impulso do desenvolvimento progressista.

Gohn refresca ainda, que a construção do Estado moderno está ancorada na Declaração dos direitos do homem, que tem na propriedade, o fundamento supremo das liberdades políticas de uma nação. Determinando que só será considerado cidadão o indivíduo que portar conhecimentos tecnocráticos para gerir suas posses e prosperá-las. Ou seja, o cidadão é o sujeito político burguês.

Por sua vez, essa natureza política que fundamenta o burguês no Estado moderno das leis, estará definida nas noções da filosofia de Diderot, no qual a propriedade faz o cidadão. Ou mesmo em Locke, o qual justifica a diferenciação de direitos entre a classe trabalhadora e a burguesia.

Locke fundamentava seus argumentos na proposição de que já que classe trabalhadora usava a força física e não a cabeça, ela seria incapaz de ter ideias sublimes, como por exemplo, os grandes filósofos que tinham acesso ao conhecimento iluminista das universidades. Sendo assim, eram considerados incapazes de pensar. E nesse caso, a ideia principal era a de como reconhecê-los, como cidadãos capazes de agir com racionalidade política posto que possuíam ações desordeiras e ameaçariam a ordem. Não obstante, não poderiam saber, precisavam apenas acreditar.

Como pondera Gohn (1994, p. 12), “a educação para a cidadania não faria parte do universo da classe trabalhadora porque ela não seria cidadã”. O resultado para essa afronta encontra-se encarnado no pressuposto formulado pelas teses do materialismo histórico, ou seja, na necessidade de uma nova revolução das posições políticas, dessa vez em que o explorado se tornasse o sujeito histórico da modificação da realidade, pois à medida que o

UFSC, Florianópolis - http://dx.doi.org/10.5007/1806-5023.2016v13n1p161 ISSN: 1806-5023 
capitalismo se consolida, a educação passa a ser pensada pelas classes dirigentes como mecanismo de controle social. Reverter esse quadro significa devolver a humanidade para as atividades humanas do trabalho, que foi retirada a partir do "fetiche da mercadoria" (MARX, 1996), e devolver o sentido de comunidade à propriedade dos meios de reprodução. Isso ressignificaria inclusive a concepção de educação.

\section{Variação histórica do controle da cidadania}

A cidadania é um conceito sócio-político de conotação eminentemente moral, do disciplinamento para o convívio social desenvolvido para evitar o conflito. O seu conceito que parece fixo e também neutro, é tema recorrente no debate da filosofia dos pensadores contratualistas.

Em contextos latino-americanos, identificam-se três práticas disciplinares contribuídas para forjar os cidadãos do século XIX, sendo elas as constituições, os manuais de urbanidade e as gramáticas do idioma (CASTRO-GOMEZ, 2005). Essas tecnologias que constrói leis são formas de subjetivação de identidades nacionais.

Não obstante, é na virada do século XIX que a cidadania passa a se definir como sinônimo de igualdade, firmada para dirimir as forças de união das massas, em vista de discipliná-las e domesticá-las de maneira coercitiva e consensual. É por isso, que as práticas pedagógicas que fazem parte da educação, irão enfatizar as estratégias de persuasão, convencimento e moralização dos sujeitos no aprendizado escolar.

Essa tática dos Estados nacionais respondeu à necessidade de ordenar e instaurar a lógica da civilização. E instituir,

Através da palavra escrita, discursos hegemônicos, mapas, gramáticas, constituições, manuais, tratados de higiene, que regulamentassem a conduta dos atores sociais, estabelecendo fronteiras que lhes transmitem a certeza de existir dentro ou fora dos limites definidos por essa legalidade (GONZALÉZ STEPHAN, 1996, s.p.)

Mas, será no século XX que o projeto burguês virá encetar a questão dos direitos dos indivíduos, como direitos baseados nos deveres, a cidadania rigorosamente definida

UFSC, Florianópolis - http://dx.doi.org/10.5007/1806-5023.2016v13n1p161 ISSN: 1806-5023 
(GOHN, 1994). Talvez por isso, não seja novidade ser esse o momento em que a escola se molda de um conteúdo romantizado. De maneira idílica e estigmatizada, o qual o livro didático representa de forma eficiente a ilusão nacional, pois essa regularidade das funções das instituições facilita administração de uma educação escolar tendencialmente pacífica, ordeira e submissa.

É coerente que o cidadão seja educado para a civilidade, dissuadido de ser um pactuante dessa comunidade de interesses a qual em real não participa. Não é à toa que o que temos hoje é uma educação conservadora, defasada e precursora de preconceitos, por conta do anseio de educar para a cooperação e para a reprodução mecanicista. É necessário que não se questione.

\section{Em síntese: a educação popular dos movimentos sociais}

Para Karl Marx a razão iluminista poderia ter servido de instrumento de construção de uma sociedade mais justa, se o conhecimento gerado pela tecnologia fosse utilizado em vantagem das capacidades humanas e desenvolvimento potencial das relações de intercâmbio equitativo. Porém, vimos em Durkheim que a socialização conservadora alinha-se aos ideais da economia, recomendando o controle da difusão do conhecimento produzido pela sociedade, de acordo com a disposição hierárquica das classes sociais, como forma de evitar desordens, e conter a anomia.

Em consequência, empreender a educação para o trabalho, assim como estabelecido nas premissas de Max Weber do sistema perito, garantirá mobilidade social exclusiva de/para a classe dominante. Já que por meio do mecanismo do sistema das legislações, as cartas cívicas, são suficientes em promover a estabilidade das divergências sociais. Ou seja, o Estado burocrático é o centro agregador das igualdades, que advoga em nome da justiça, a inclusão das personalidades, enquanto personalidade de cooperação com o projeto de desenvolvimento.

Em contrapartida, os movimentos sociais no decorrer desse percurso, continuam esforçando em devolver o conceito de comunidade e solidariedade que, como vimos, foram retirados das concepções da sociedade moderna, realinhando seus significados de maneira

UFSC, Florianópolis - http://dx.doi.org/10.5007/1806-5023.2016v13n1p161 ISSN: 1806-5023 
mais próxima às perspectivas reais. Apostam num caráter educativo que considere a organização política, fomento da cultura política e o reconhecimento das condições de vida.

Como exposto, pondera Gohn que a luta pela moradia e pela terra traz no bojo de sua conjuntura um processo de educação crítica, real. As associações e movimentos comunitários propõem engajamento cotidiano com o espaço habitado. A participação é marcada pelo assembleísmo, participação direta. Mutirões comunitários, passeatas, construção de habitações populares, unindo articulação entre a base dos movimentos sociais e as suas lideranças para com assessorias externas, ou os partidos.

Um belo exemplo de mobilização dessa grandeza é o projeto da Escola Nacional Florestan Fernandes (ENFF) ${ }^{5}$, construída entre 2000 e 2005 por trabalhadores sem terra e colaboradores simpatizantes da sociedade civil. O projeto tem como missão educativa a formação de militantes de movimentos sociais na energia de resistência contra a ofensiva dos donos do capital. Funciona em mais de uma unidade, pelo Brasil, a partir da organização de recursos independentes que mostra ser possível que trabalhadores tornem-se sujeitos conscientes da sua própria história. As atividades são realizadas de maneira inteiramente autônoma da agenda escolar controlada pelo Estado classista, ou pela classe estatal $^{6}$.

Moema Viezzer (1989) esclarece que a militância comunitária revela um "grau de amadurecimento para outras questões”, que não ser refere estritamente à localidade, ou à comunidade em que habitam, mas serve para demonstrar globalmente que é possível resgatar o papel transformador dos processos educativos, em contraposição à duvidosa conformação das consciências apáticas que ideologia dominante quer incutir no terreno da educação, sendo que ao ser tratada pelos setores populares, esses setores lhe darão outra direção de conteúdo.

Notamos que existe um esforço recorrente de manutenção da hierarquia, que assume na educação as potencialidades para a guinada de projetos políticos. Já que fica evidente que a história humana da perspectiva das relações de poder se desenvolve a partir do

\footnotetext{
${ }^{5}$ Nos últimos tempos, cresceram as experiências educacionais populares pela América Latina. Assim é caso da Universidade Popular de las Madres de la Plaza de Mayo, na Argentina; A Universidade Livre Feminista; Universidade Popular dos Movimentos Sociais, dentre muitos outros casos.

${ }^{6}$ Fonte dos dados: Associação de Amigos da ENFF.
}

UFSC, Florianópolis - http://dx.doi.org/10.5007/1806-5023.2016v13n1p161 ISSN: 1806-5023 
domínio das forças populares pelos grupos de elite. Esse elemento que nos foi deixado estanque na exposição que seguiu, aponta para o perigo que representa a intervenção popular no ato de produzir a sua própria história.

Por isso, não é a toa que o principal elemento de disputa por hegemonia está expresso nas formas de disponibilização do acesso ao conhecimento, que pode ser acrescentado de conteúdo prepotente ou libertário, mas o fato é que este conteúdo é retransmitido pela educação.

Assim sendo, assombrado pela iminência de perigo à estabilidade hegemônica, as classes dominantes capturam os significados de cidadania, solidariedade e comunidade, recolocando-os sob significados próprios, tal como é apreendido do modelo educacional oferecido por Max Weber, a burocracia.

A burocracia cria tipos sistemáticos de diferenciação, os escreve nas leis. Esse é fato suficiente que denuncia a falsa neutralidade do sistema de 'meritocracia', pois dentro do modelo capitalista de viver, situações de mérito não são próprias do ser social, mas do poder que ele encena. São situações fomentadas pela própria burocracia, e estão fundamentadas na natureza das relações de expropriação.

Finalmente, tentei esboçar que existe um pressuposto de que a educação intelectual, corporal e tecnológica, está capturada para o engajamento compulsório na ideologia dominante, e que a educação não precisa estar articulada para cindir com habilidades humanas e agrupá-las por meio de concepções simbólicas, mediada pelo dinheiro.

A educação tem condições de ser criativa, envolvente e fomentar o pensamento crítico nos seres humanos. Os seres humanos são seres políticos, distintos e capazes de articular-se em prol de suas necessidades enquanto tal. Não necessitam reconhecerem-se a partir das coisas que circulam num mercado de consumo tosco, cruel e prolixo. Os sentidos de solidariedade e comunidade são mais eficientes se fundamentados na alteridade das experiências, do que por meio de fetichizações do outro. As relações humanas são dotadas de sentido, a partir da reflexividade das ações sociais.

\section{Referências}


CASTRO-GOMÉZ, Santiago. Ciências Sociais, violência epistêmica e o problema da "invenção do outro". In: CLACSO, ColecciónSurSur, Buenos Aires, Ar: Setembro de 2005.

BERGER, Peter L.; LUCKMANN, Thomas. A construção social da realidade: tratado de sociologia do conhecimento. 22.ed. Petrópolis ; Rio de Janeiro: Vozes, 2002.

DURKHEIM, Émile. Educação e sociologia. 11. ed. Sao Paulo: Melhoramentos, 1978.

GIDDENS, Anthony. As consequências da modernidade. São Paulo: Ed. UNESP, 1991.

GOHN, Maria da Gloria Marcondes. Movimentos sociais e educação. 2. ed. São Paulo: Cortez, 1994.

GONZÁLEZ STEPHAN, Beatriz. Economías fundacionales. Diseño del cuerpo ciudadano. In: González Stephan, B. (org.) Cultura y Tercer Mundo. Nuevas identidades y ciudadanías. Caracas: Nueva Sociedad, 1996.

MARX, Karl; ENGELS, Friedrich. Manifesto do partido Comunista. Porto Alegre, RS: L\&PM, 2001.

MARX, Karl. O capital: Crítica da Economia Política, Livro Primeiro: o processo de produção do capital, TomoII. São Paulo, SP: Nova Cultural, 1996.

. A Miséria da Filosofia. São Paulo, SP: Global, 1985.

MARTINS, José de Souza. Introdução crítica à Sociologia Rural. São Paulo, SP: Hucitec, 1981. 
QUINTANEIRO, Tania; BARBOSA, Maria Ligia de Oliveira; OLIVEIRA, Márcia Gardênia de. Um toque de clássicos: Marx, Durkheim e Weber. 2. ed. rev. e ampl. Belo Horizonte: Ed. UFMG, 2010.

LOPES, Paula Cristina. Educação, Sociologia da Educação e Teorias Sociológicas Clássicas: Marx, Durkheim e Weber. Biblioteca Online de Ciências da Comunicação, 2012.

VIEZZER, Moema: O problema não está na mulher. São Paulo: Cortez, 1989.

WEBER, Max. Ensaios de sociologia. 4. ed. Rio de Janeiro: J. Zahar, 1979. 


\title{
O que se entende por Educação: as abordagens da Sociologia clássica de Durkheim, Weber e Marx
}

Resumo: A Educação é um tema chave na sociedade moderna. Sabemos hoje que o projeto moderno de civilização se utilizou da Educação para consolidar sua tirania de colonização e controle hegemônico. Por esse motivo, tivemos por bastante tempo, apenas uma concepção do que é Educação, mas que isso tem mudado. Por conseguinte, o imaginário social ainda remete ao conservadorismo do tema, pois toda vez que perguntado o que se entende por Educação, automaticamente relacionamos às praticas escolares de treinamento técnico. Por esse motivo, o presente trabalho procura refletir sociologicamente a respeito da Educação. Para isso utiliza do percurso das teorias clássicas da Sociologia, visando fugir do padrão normativo, para tentar pensar possibilidades de projetos educacionais com autonomia.

Palavras-chave: Educação; Clássicos da Sociologia; Teoria Sociológica.

\section{What is understood by education: the approaches of classical sociology of Durkheim, Weber and Marx}

\begin{abstract}
Education is a key subject in modern society. Today we know that the Modernity's project of civilization have used education to consolidate your colonization and hegemonic control. For that reason, for a long time we have only one conception of education; bur that is changing. Thereafter, the social imaginary still forward to the conservative meaning of the subject. For every time one asks on Education, the answer is correlated to school practices of technician training. For that reason, this paper reflects sociologically on education. In order to that, trail the route of the classics theories of sociology, aiming to escape of this hegemonic pattern and to think possibilities of educational projects with autonomy.
\end{abstract}

Key-Words: Education, Sociology Classics, Sociological Theory. 
Recebido em: 08 de abril de 2016.

Aceito para publicação em: 31 de maio de 2016. 